\title{
MECHANISMS OF ENDOCRINE DISEASE
}

\section{Sarcopenia in endocrine and non-endocrine disorders}

\section{Victoria Zeghbi Cochenski Borba', Tatiana Lemos Costa', Carolina Aguiar Moreira ${ }^{1,2}$ and Cesar Luiz Boguszewski}

${ }^{1}$ Endocrine Division (SEMPR), Hospital de Clinicas, Federal University of Paraná, Curitiba, Brazil and ²Pro-Renal Brasil, Lab PRO, Bone Histomorphometry Section, Curitiba, Brazil
Correspondence should be addressed to V Z C Borba

Email

vzcborba@gmail.com

\begin{abstract}
Objective: This paper reviews the main mechanisms, diagnostic criteria, treatment options and available data on sarcopenia in endocrine and non-endocrine disorders. The literature notes the presence of sarcopenia as a comorbid condition or a complication of another clinical situation and not a disease that only affects elderly patients.

Method: We performed a literature review, focusing on the following: mechanisms related to sarcopenia in elderly patients, and sarcopenia as it presents in the context of chronic and endocrine diseases; diagnostic tools and methods; aspects of sarcopenia and treatment options specific to chronic diseases and endocrine disorders respectively. Results: Sarcopenia in chronic and endocrine disorders shares many mechanisms with sarcopenia affecting elderly patients, but certain diseases can have a predominant aspect that leads to sarcopenia. The prevalence of sarcopenia varies, depending on different diagnostic criteria, from around 12 to $60 \%$ in chronic illnesses and 15 to $90 \%$ in endocrine disorders. The interplay between sarcopenia, chronic diseases and elderly patients requires further study, to clarify the impact of each, in terms of prognosis and mortality. Conclusion: Awareness of the presentation of sarcopenia in the context of other diseases and ages (and not just the elderly) is fundamental to ensure that preventive measures can be deployed.
\end{abstract}

\section{Introduction}

Sarcopenia is a loss of muscle mass (MM) and strength, initially believed to affect mostly elderly patients. The condition is referred to as primary sarcopenia, when no other cause is present, and secondary, when a specific cause is involved (1). It is highly prevalent among elderly patients; a meta-analysis of 35 articles, which included

\section{Invited Author's profile}

Victoria Borba is the Adjunct Professor, Department of Internal Medicine, Division of Endocrinology, Federal University of Paraná, Curitiba, Brazil. Since 2017 she has been the Chief of the Serviço de Endocrinologia e Metabologia do Hospital de Clinicas, Universidade Federal do Paraná (SEMPR). Victoria mostly works with medical students, residents and post-graduate students completing their Masters and PhD programs and in clinical research with graduate and postgraduate students on different subjects: vitamin D in chronic illness; osteoporosis and sarcopenia

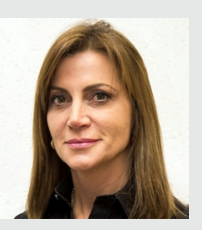
in the elderly, and chronic diseases; body composition in healthy individuals; effects of calcium and vitamin $\mathrm{D}$ and physical training in falls.

Published by Bioscientifica Ltd 
normal community-dwelling participants, aged 60 years and older, showed sarcopenia to have a $10 \%$ prevalence, that reached 20\% when bioelectrical impedance analysis (BIA) was used for diagnosis (2).

The aging process, characterized by a progressive decline of $\mathrm{MM}$ and function, is often accompanied by different comorbid conditions that can contribute to the development of sarcopenia. Indeed, sarcopenia has been described as presenting in the context of many chronic diseases, including endocrine disorders, and not only in elderly patients; it can be a cause or a consequence of the underlying disease contributing to the prognosis (3). Distinguishing between age-related sarcopenia and disease-specific sarcopenia is difficult, because of the frequent interrelationships between these entities. Independent of age, the loss of $\mathrm{MM}$ and strength is related to the worst rates of morbidity and mortality in various diseases, which reflects the extent to which sarcopenia can impact the treatment outcome.

There are no specific recommendations for diagnosing sarcopenia in patients with chronic illnesses, and although the diagnostic criteria were initially intended to refer to sarcopenia among the elderly, they have been applied to other populations (4). Recognizing sarcopenia when it presents in the context of chronic diseases is of fundamental importance, as sarcopenic communitydwelling older adults showed a threefold increase in mortality, over 3 years of observation, relative to nonsarcopenic patients (5).

This paper reviews the main mechanisms and diagnostic criteria of sarcopenia, as well as the present data on sarcopenia in endocrine and non-endocrine disorders, along with the relevant treatment options.

\section{Mechanism of sarcopenia in non-endocrine and endocrine diseases}

The pathogenesis of sarcopenia in chronic and endocrine disorders share many features with the presentation of sarcopenia in the aging process; one specific process could be relevant to a particular condition and irrelevant to another (for example, insulin resistance and autophagy for type 2 diabetes), but the majority of the mechanisms are connected (4).

The most commonly described mechanisms are as follows: lack of muscle or physical activity and low motor unit remodeling; disproportion between protein syntheses and regeneration, with post-prandial resistance to anabolism; hormone and cytokine imbalance, involving sex hormones (e.g. testosterone, dehydroepiandrosterone), vitamin D, growth hormone (GH), IGF-1 and cortisol; the presence of myostatin and proinflammatory cytokines (tumor necrosis factor (TNF) and interleukin 6 (IL-6)); oxidative stress and mitochondrial dysfunction, with an accumulation of reactive oxygen species $(1,3)$. Figure 1 outlines the mechanisms involved in the pathogenesis of sarcopenia, which will be explained in more detail for each disease, according to references $(3,6,7)$.

\section{Diagnostic criteria}

The diagnostic criteria of sarcopenia have been through changes that have tried to reach the clinical setting. Since Baungartner's definition of sarcopenia (8), based only on low $\mathrm{MM}$, a diverse set of sarcopenia opinions and definitions, with similarities and differences have been published.

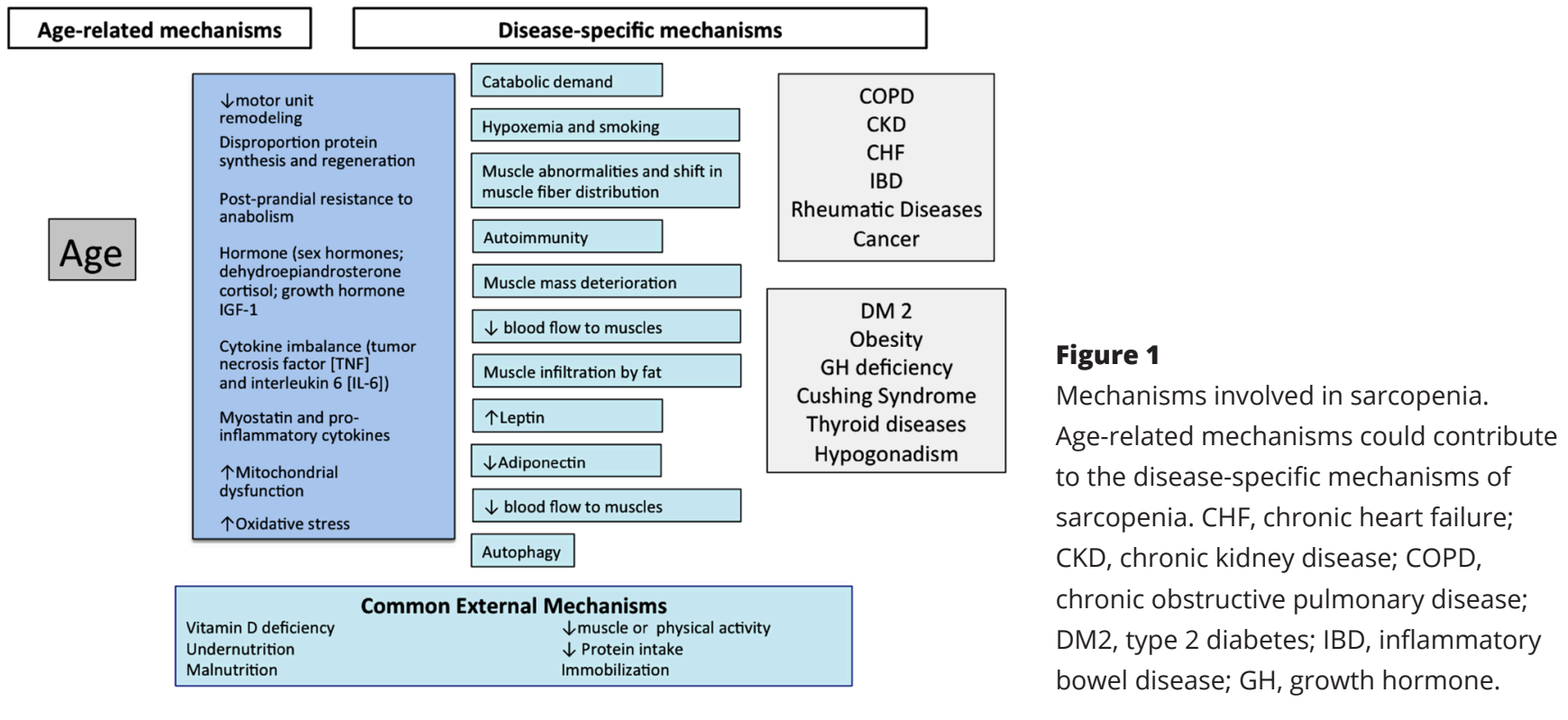


In 2010, the European Working Group on Sarcopenia in Older People (EWGSOP) recommended the inclusion of an assessment of muscle quality, for the purposes of diagnosis. The starting point was measurement of MM (i.e. quantity), and its loss was named pre-sarcopenia. Sarcopenia was diagnosed when muscle weakness or low function was associated with this loss of MM; if all three characteristics were present, severe sarcopenia was identified, thereby providing a mode of stratifying the disease, according to severity (1). Later on, others published definitions that were characterized by few variations in cut-off points or methods for measuring $\mathrm{MM}$, strength or performance $(7,9,10,11,12,13)$.

With the objective of facilitating diagnosis for clinicians, the Foundation for the National Institute of Health Sarcopenia Project (FNIH) pooled data from a series of clinical trials, including 26,625 participants, in an evidence-based approach to generating recommendations (9). They published five papers on different diagnostic criteria for sarcopenia, from grip strength (14) to low MM (15), articulating longitudinal predictions based on weakness and $\mathrm{MM}$ criteria, and detailing comparisons between the definition of sarcopenia identified by the FNIH and previous definitions of sarcopenia. The starting point for diagnosing sarcopenia was low physical function, only after such a determination, should MM be measured. This approach enabled the use of a clinical screening before measuring MM, which requires more sophisticated methodology. FNIH experts evaluated and integrated the influence of body mass on different diagnostic cut-off points, to arrive at a more conservative operational definition (16) .

In 2018, the EWGSOP published a new algorithm (EWGSOP2), recommending a case-finding tool aimed at screening sarcopenia. A positive SARC-F questionnaire or clinical suspicion should be present, to justify measuring muscle strength (i.e. grip strength or chair-standing test), after which muscle quantification and quality evaluation can be used to confirm sarcopenia. Any test of altered physical performance (e.g. gait speed, short performance physical battery (SPPB), timed to get up and go (TUG) or $400 \mathrm{~m}$ walk) can be used to classify a condition as severe sarcopenia (7). Other diagnostic panels and group opinions were published and are displayed in Table 1.

\section{Methods for evaluating sarcopenia}

The diagnostic approaches vary, depending on the recommendation; the main diagnostic tools, according to newer recommendations, are cited below. Figure 2 shows a stepwise method to evaluate sarcopenia created according to EWGSOP2 (7).

\section{Clinical questionnaires}

Questionnaires are proposed as an initial screening test to confirm clinical suspicions or avoid further investigation. The Mini Sarcopenia Risk Assessment (MSRA) questionnaire investigates anamnestic and nutritional characteristics related to the risk of sarcopenia (17); SARC-F is an easy-toapply questionnaire that asks daily-life questions, seeking answers based on the patient's perception of his or her limitations in strength, walking facility, capacity to rise from a chair, stair-climbing and any associated experiences with falls; a score $\geq 4$ is predictive of sarcopenia and a poor outcome (18). Both questionnaires have demonstrated similar diagnostic accuracy, although SARC-F has offered better specificity. The EWGSOP2 included SARC-F as the first screening tool to diagnose sarcopenia (7).

\section{Muscle strength}

Muscle strength can be assessed by different techniques; before determining which technique should be used, the purpose, cost, availability and applicability of the method should be considered (7). The manual grip strength test has been widely used, and it correlates well with physical performance, ability to perform daily activities, quality of life and mortality (14). The most used device in clinical practice is the hand-grip dynamometer, for which different diagnostic cut-off points have been used, as shown in Table 1. The modern, commercial isokinetic dynamometers allow both isometric and isokinetic measurements of strength and reflects muscle function in everyday activity (1). The chair stand test is a simple mode of evaluating strength and endurance in clinical practice when there is a disability that could compromise the hand-grip evaluation; it relies on evaluating the strength of the quadriceps muscle, over the amount of time needed to rise five times from a seated position, without the aid of arms. The timed chair stand test is a variation that counts how many times a patient can rise and sit in a chair over a 30-s interval (19).

\section{Physical performance}

Physical performance tests give a multidimensional evaluation of whole-body function, related to locomotion; they also analyze muscles, as well as central and peripheral nervous function, including balance. For the EWGSOP 


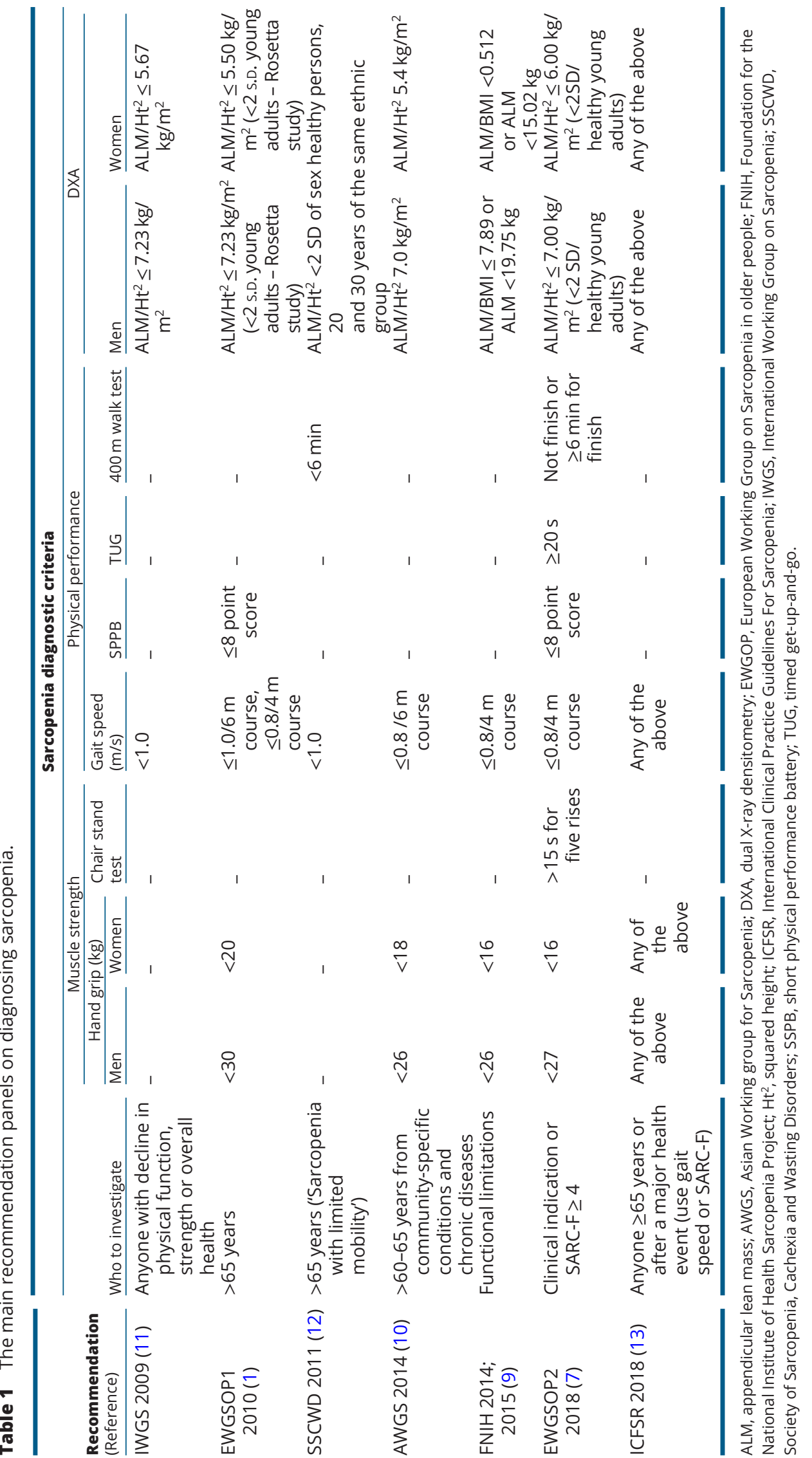




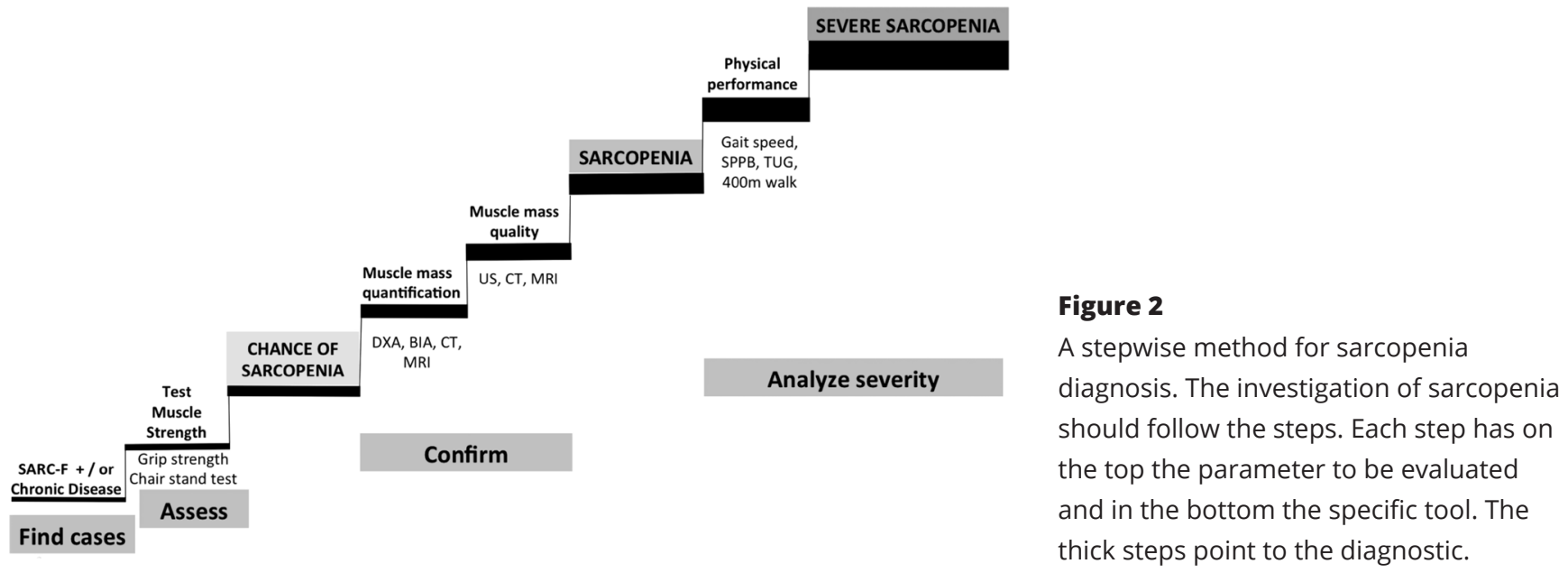

and FNIH, gait speed is considered a quick, safe and highly reliable test, widely used in practice, and recommended for evaluating performance that, when altered, justifies the classification of sarcopenia as severe $(7,9)$. The test requires a subject to move $4-6 \mathrm{~m}$ at a usual walking speed, and results are indicative of sarcopenia when speed $\leq 0.8 \mathrm{~m} / \mathrm{s}$. The TUG is another easy-to-use test, in which individuals are asked to rise from a standard chair, walk to a marker $3 \mathrm{~m}$ away, turn around, walk back and sit down again (20). The Short Physical Performance Battery (SPPB), useful in research, is composed of three tests, including gait speed, a balance test and a chair stand test; a score $\leq 8$ points is indicative of poor physical performance. All these tests, as well as others not shown here, can predict sarcopenia-related outcomes, such as disability, cognitive impairment, a need for institutionalization, falls and mortality (21).

\section{MM evaluation}

There are many possible methods for evaluating MM, the majority of which give indirect measurements; given that MM varies, according to the amount of water in the body, its evaluation has advantages and limitations worth considering.

Magnetic resonance imaging (MRI) and computed tomography (CT)

MRI and CT are the gold standards of MM evaluation. However, the high costs, low availability, technical difficulties, impact their standardization for clinical use. Both types of scans can quantify bone, muscle, visceral organs and adipose tissue, differentiating between subcutaneous and visceral fat. They can measure muscle quantity and quality, intra-and extra-myocellular lipid deposition, and also estimate fiber-type composition (21).

\section{Dual energy Xray absorptiometry (DXA)}

DXA is currently the reference method for estimating total body composition. DXA has many advantages, including low radiation, provides measurements of muscle, fat and bone mass. Moreover, it is fast, costs less than MRI and CT, permits the estimation of appendicular skeletal muscle (ASM) mass, and it is reproducible with the same equipment and cut-off points (7). Its disadvantages are that it is neither portable nor available in primary care settings. Results could be affected by body thickness, hydration status and water retention. Additionally, MM could be overestimated in the presence of edema and obesity (by underestimating trunk and thigh fat mass, and overestimating thigh MM). To minimize this effect, absolute ASM or skeletal MM can be adjusted, for squared height, BMI or weight (21).

\section{Bioelectrical impedance analysis}

BIA indirectly measures MM, through whole-body electrical conductivity. MM is calculated using the equation developed by Janssen. BIA is inexpensive, easy to use, widely available and portable; however, measurements should be acquired under standard conditions to avoid variability, due to hydration status, consumption of food and beverages, ambient air and skin temperature and recent physical activity (21). It is appropriate for both ambulatory and bedridden patients. MM differs with different instruments and reference population; EWGSOP2 advises use of raw measures, along with the cross-validated Sergi equation, for standardization (7) 


\section{Alternative techniques for MM evaluation}

Ultrasound

Ultrasound (US) can quantify tissue thickness, measure the cross-sectional area of individual muscles, identify muscle wasting and also evaluate muscle quality with high test-retest reliability (21). It is radiation-free and portable, which permits its bedside and sequential use. Relative to DXA, MRI and CT, US showed good reliability and validity in predicting lean mass. US has great potential for clinical use in the near future, when more data will be available for older adults and across different health conditions (22).

\section{Deuterated creatine (D3-creatine) dilution}

The creatine produced endogenously or ingested with foods is absorbed mainly by muscle cells, converted into phosphocreatine and excreted in urine. An oral dose of deuterated creatine (D3-creatine) can be quantified in urine and measures whole-body creatine pool size, and thus, skeletal MM. Although concordance with MRI has been observed, its clinical use is limited (21).

\section{Anthropometry}

Typically used as a screening tool for sarcopenia in primary care settings or large epidemiological studies, anthropometry is a portable, easy-to-use, inexpensive and noninvasive technique. Mid-arm muscle circumference (MAMC) and calf circumference (CC) reflect both health and nutritional status and predict performance and survival in older people (23).

\section{Biochemical markers}

Biomarkers of the neuromuscular junction, muscle protein turnover, behavior and inflammation pathways, redox-related or hormones or other anabolic factors to evaluate MM have been studied; however, they have shown important limitations for inclusion among standard modes of evaluating sarcopenia (21).

\section{Sarcopenia in non-endocrine diseases}

The presence of sarcopenia leads to an increase in morbidity and mortality in some chronic diseases such as cancer and chronic obstructive pulmonary disease (COPD) (4). The progressive loss of weight, lean and fat mass, in COPD is the result of increased catabolic demand from the respiratory muscles, elevated levels of proinflammatory cytokines and oxidative stress, hypoxemia and smoking (24). The frequency of sarcopenia in patients with COPD ranges around $12-20 \%$ and is associated with a worse prognosis (25) and disease severity (26). In chronic kidney disease (CKD) patients, the MM loss presents earlier and much more markedly than in subjects without chronic illnesses. This loss may be attributed to a negative balance of protein homeostasis, with increased catabolism impaired regeneration and elevated myostatin. The prevalence of sarcopenia in CKD varies from $9.8 \%$ to $28.7 \%$ in nondialysis patients (27), up to around 33.1\% in dialysis patients (28). In advanced stages of chronic heart failure disease $(\mathrm{CHF})$, the loss of skeletal $\mathrm{MM}$ is commonly observed. The prevalence of sarcopenia varies from 20 to $47 \%$ (29), in outpatients with CHF with reduced ejection fraction, reach $19.5 \%$ and is up to $47 \%$ in younger patients ( $<55$ years of age) with dilated cardiomyopathy (30). MM is the major determinant of resting energy expenditure and exercise capacity. Inflammatory and systemic autoimmune diseases are etiological factors associated with sarcopenia. In inflammatory bowel disease (IBD), the prevalence of sarcopenia varies from 27 to $61 \%$ (31). Patients with rheumatic diseases are especially predisposed to developing sarcopenia (up to 20\%), in light of their underlying proinflammatory state and decreased muscle use, inactivity and pain, they experience three times the loss of MM and functionality (32). In cancer, the etiology of sarcopenia is multifactorial and shares many factors of elderly sarcopenia (33). The prevalence is variable, depending on the cancer type and diagnostic methods; few oncological studies have used the combined criteria of low MM and impaired muscle function. A recent metaanalysis, of 7843 patients with solid cancer showed a prevalence of sarcopenia ranging from 11 to $74 \%$ (34).

\section{Sarcopenia and endocrine disease}

\section{Diabetes mellitus}

Damage to the skeletal muscles has been described as a new complication of diabetic patients attributed to their longer survival (35). Sarcopenia occurs earlier, between 50 and 60 years, in persons with type 2 diabetes mellitus (DM2) and is strongly associated with increased frailty, mortality, higher hospitalization rates, disability and cardiovascular events, relative to non-frail patients with diabetes (36). Sarcopenia could be a potential cause and a consequence of the disease (36), it is likely that significantly lower 
skeletal MM results in the reduced capacity for glucose disposal in older adults with sarcopenia, engendering a vicious cycle (37). The reduced oxidative capacity of aging muscle, mitochondrial dysfunction and chronic lowgrade inflammation are associated with insulin resistance. The higher the hemoglobin A1C (>8.5\%), the worst the presentation of sarcopenia (38). The recognition that loss of muscle results in loss of insulin receptors explains the association with poor diabetes control. Other specific causes of muscle loss in diabetes are the neuropathy; low testosterone; obesity; reduced mTOR, which regulates protein synthesis in insulin resistance and decreased blood flow to the muscles. Moreover, comorbidities, such as decreased visual acuity, heart failure and peripheral arterial disease, result in decreased physical activity $(36,39)$.

The association with sarcopenia is three times higher among diabetics than controls, but it could be eight times higher (16\%), as described by Trierweiler et al. (35), and yet still greater in latent autoimmune diabetes of adult (LADA) patients (35\%), relative to controls (9.8\%) (39). The ability to recognize at-risk individuals, and take preventive actions or undertake treatment, could avoid further MM deterioration.

\section{Obesity}

Sarcopenic obesity is generally defined as the increase of fat mass in elderly patients, without adequate parallel growth of $\mathrm{MM}$ and strength. There is no consensus on the definition of sarcopenic obesity, and the relevant methodological issues and clinical thresholds remain subject to debate. The current definitions combine sarcopenia, defined according to variable criteria, with the presence of obesity, defined as either a BMI $>30 \mathrm{~kg} / \mathrm{m}^{2}$ or by adiposity levels (40).

Profound skeletal muscle metabolism changes may occur in cases of obesity and may lead to altered body composition with increased fat mass and substantial impairment of MM quantity and quality. Therefore, the pathogenesis of sarcopenic obesity is multifactorial, with an interplay between the common mechanisms of agerelated sarcopenia associated with chronic inflammatory response, unleashed by the infiltration of adipose tissue by immune cells, which increases adipokines and cytokines to create a condition of low-grade inflammation, leading to a decline in physical activity that worsens IR. This mechanism is one of the key factors involved in creating and maintaining a vicious cycle of decreased muscle strength in elderly and obese patient (41).
More importantly, sarcopenic obesity was shown to increase all-cause mortality and disability (42).

As mentioned earlier, the diversity of criteria used in diagnosing sarcopenic obesity results in a variable reported prevalence, ranging from 4.4 to $84.0 \%$ in men and from 3.6 to $94.0 \%$ in women. When the FNIH criteria was applied to the National Health and Nutrition Examination Survey (NHANES) cohort, rates of sarcopenic obesity were $12.6 \%$ in men and $33.5 \%$ in women, rates that increased with age $(42,43)$.

Changes in body composition after bariatric surgery, such as a sustained loss of body fat, are associated with an unavoidable loss of lean body mass (LM). LM accounted for $27.7 \%$ of total weight loss achieved 1 year after Roux-en-Y gastric bypass (RYGB). This imbalance leads to an undesirable disturbance in resting metabolic rate, body temperature and even weight maintenance (44). Changes in body composition, dietary intake and substrate oxidation from baseline were equal in RYGB and sleeve gastrectomy. The prevalence of sarcopenia in this population of patients is so far unknown (45).

\section{Cushing syndrome}

Muscle weakness is one of the clinical characteristics of Cushing syndrome (CS), studied in a small series of patients, affecting from 40 to $70 \%$ of patients and is more pronounced in women (46). The proximal musculature of the lower limbs is the most affected. Accordingly, patients typically complain about an inability to get up from a squatting position or to climb stairs, whereas running or walking is less frequently affected (47).

Glucocorticoids are known to change muscle fiber composition and strength, with loss of type II fibers (strong and fast-contracting), even after a short period of treatment. Excess cortisol has significantly adverse effects on muscle, through 11ß-hydroxysteroid dehydrogenase type 1 enzyme (11ßHSD1), blunting muscle protein synthesis, activating muscle proteolysis, impairing mitochondrial function and decreasing sarcolemmal excitability. Cortisol, directly and indirectly, leads to muscle catabolism, insulin resistance and diabetes with all mechanisms implicated. Increased insulin resistance and hypercortisolism lead to fat deposition in muscle, decreased oxidative capacity of muscle and fiber loss. Insulin resistance contributes to sarcopenia via inhibition of the nitric oxide cascade, resulting in lower absorption of available amino acids for protein synthesis. Increased inflammatory cytokines from fat leads to further muscle catabolism. Moreover, prolonged inactivity in 
the establishment of excess cortisol appears to sensitize skeletal muscle to the catabolic effects of cortisol (48).

The muscle and fat masses are similar in patients with CS, relative to obese patients, adjusted for age and gender. However, muscle function is strongly impaired in CS patients, owing to increased intermuscular fat infiltration. Even subtle amount of excess cortisol in women with subclinical hypercortisolism can decrease skeletal MM, especially of the lower limbs (49). Similar to cognitive function, there is a longstanding effect of CS on muscle function that can last for short- (6-8 months) or long-term ( $>2$ years) periods after successful treatment of CS (50).

\section{Osteosarcopenia}

Sarcopenia and osteoporosis share common risk factors and biological pathways and are associated with significant physical disability, representing a huge threat of lost independence in later life, and significantly increasing the mortality rate. The combination of these two diseases has been described as a 'hazardous duet' that combines the propensity of falls from sarcopenia with the vulnerability of bones in patients with osteoporosis (51).

There is abundant evidence that changes in bone mass are closely associated with changes in MM. A direct correlation between bone and muscles has been observed. However, it is not clear which starts first, sarcopenia or osteopenia. Many shared pathways are involved in this interaction and can explain the development and progression of osteosarcopenia. Apart from age, several other risk factors play a role in the development of osteosarcopenia, with an array of mechanical, biochemical, genetic polymorphisms and lifestyle factors all contributing to involution of the 'bone-muscle unit', including reduced physical activity observed in aging. Important hormones mediating this crosstalk include GH, insulin-like growth factor-1 (IGF-I), sex hormones and vitamin $\mathrm{D}$, which are subject age-related decreases contributing to the development of osteosarcopenia, along with inflammatory cytokines, myokines and osteokines, which promote communication between them $(52,53)$.

Epidemiology data of osteosarcopenia are fairly limited because of the term's recent origin. However, one study of 680 elderly adults with a history of falls found a $37 \%$ prevalence of osteosarcopenia, with higher frequency comorbidities, impaired mobility and depression (54). A study of Chinese adults ( $\geq 65$ years old) identified osteosarcopenia in $10.4 \%$ of men and $15.1 \%$ of women, with higher odds of frailty in the osteosarcopenics, relative to osteopororic or sarcopenic patients alone (55). In patients with hip fractures and osteosarcopenia, the 1-year mortality rate was $15.1 \%$, compared to $5.1 \%$ for osteoporotic or $10.3 \%$ for sarcopenic patients (56). Future therapies could embrace both osteoporosis and sarcopenia by targeting pathways that affect both muscle and bone.

\section{GH deficiency}

Besides its well-established role in promoting longitudinal growth, GH has important metabolic and anabolic functions. GH stimulates both bone and muscle anabolism, either through a direct effect via GH receptors (GHR) or an indirect effect via stimulation of hepatic and non-hepatic insulin-like growth factor I (IGF-I) production (57). It is known that aging is associated with a progressive decline of GH and IGF-I secretion, a physiological process often referred to as somatopause $(58,59)$ which has even been replicated in a group of active cyclists (60). These findings are likely a reflection of a reduced ghrelin/GHRH input in aged subjects, as the GH secretion in older subjects is reversible with GH secretagogues $(61,62)$. IGF-I levels have been independently associated with $\mathrm{MM}$ and physical performance in men, but not women, among communitydwelling middle-aged and elderly populations $(63,64)$.

GH and IGF-I muscle anabolism could be seen in vitro and in animal models in vivo (65). However, physiological and supraphysiological levels of circulating GH and IGF-I have not had demonstrably profound effects on MM in healthy humans, contrasting with the reduced muscle and bone mass and increased fat mass observed in patients with Laron syndrome, due to GHR mutations, and in adult patients with acquired hypopituitarism and GHD $(66,67)$. However, reduced MM associated with human GHD is not always indicative of dysfunction, whereas better-adjusted muscle strength parameters and greater peripheral resistance to fatigue were described in severe isolated GHD cases (68).

Such contrasting findings should be kept in mind when analyzing the implications of GH therapy in sarcopenia of GHD and non-GHD individuals. In older non-GHD individuals, a recent systematic review and meta-analysis have led to the conclusion that GH supplementation is not an appropriate therapy for sarcopenia, as $\mathrm{GH}$ increases $\mathrm{MM}$ without improving muscle strength or physical performance and is associated with high incidence of adverse events. The same was true for the use of GH-releasing hormone (GHRH) or IGF-1 supplementation in older people (69). It is worth noting here that combining GH therapy with resistance exercise 
or testosterone supplementation is also of little value, very limited or no impact on muscle performance in elderly individuals $(69,70)$.

Twelve-month supplementation of GH reduced fat mass and increased $\mathrm{MM}$, without commensurate change in strength and endurance. Instead, 24 hypopituitary GHD adults over the age of 60 years, receiving GH replacement therapy for 10 years, observed a transient increase in isometric knee flexor strength and prevented age-related decline in muscle performance and neuromuscular function (71). Even systematic reviews of this topic have not produced consistent findings; one meta-analysis found strong evidence that GH replacement improves exercise performance in GHD patients, and 1 year later, another meta-analysis showed improvement in aerobic exercise capacity and MM, without incremental muscle strength improvement $(72,73)$. Taken together, data indicate that GH therapy in GHD adults is associated mainly with muscle gain, while effects on muscle function and performance are variable and likely dependent on other factors.

\section{Other endocrine diseases and sarcopenia}

Sarcopenia may be present with several endocrinopathies, including male hypogonadism and hyperthyroidism. Testosterone levels decline 1\% per year from 30 years of age half in consequence of increased fat mass that occurs with aging, associated with both hypothalamic dysfunction and a decreased response to gonadotrophins in Leydig cells leading to reduced testosterone production. Hypogonadism is associated with aging and secondary sarcopenia. Studies have consistently reported associations between low testosterone levels and inferior body composition in men. The possible mechanisms linking sex hormones with body composition include effects of adiposity on sex hormone-binding globulin (SHBG) levels, effects of testosterone on regulation of mesenchymal stem cell differentiation and muscle protein synthesis, activation of inflammatory pathways or increases in cortisol $(74,75)$. A sarcopenia prevalence of $40-50 \%$ has been observed in hypogonadal patients with CKD or cirrhosis.

Thyroid hormones regulate the expression of at least 607 genes in muscle tissue, which are involved primarily in energy and fuel metabolism. Hyperthyroidism increases protein turnover leading to the loss of $\mathrm{MM}$, accelerates thermogenesis and induces gluconeogenesis and lipolysis by metabolizing amino acids from muscles and free fatty acids from adipose tissue that result from a constant and high production of energy (76). Studies have shown a decrease of up to $20 \%$ in $\mathrm{MM}$ and $40 \%$ in strength in hyperthyroidism, which improves after treatment (77). Table 2 shows frequent diseases where sarcopenia should be investigated.

\section{Treatment}

Currently, the standard treatment for sarcopenia relies on resistance training and dietary supplements, with minimal evidence for any beneficial effects of pharmacological treatment. Treatment strategies are similar for sarcopenia, age-related or not, although identification of a specific cause is of fundamental importance to determining an appropriate course of treatment. The main approaches to treating sarcopenia are cited below. Figure 3 resume the tools to treat sarcopenia.

Table 2 Frequent diseases and clinical conditions associated to sarcopenia.

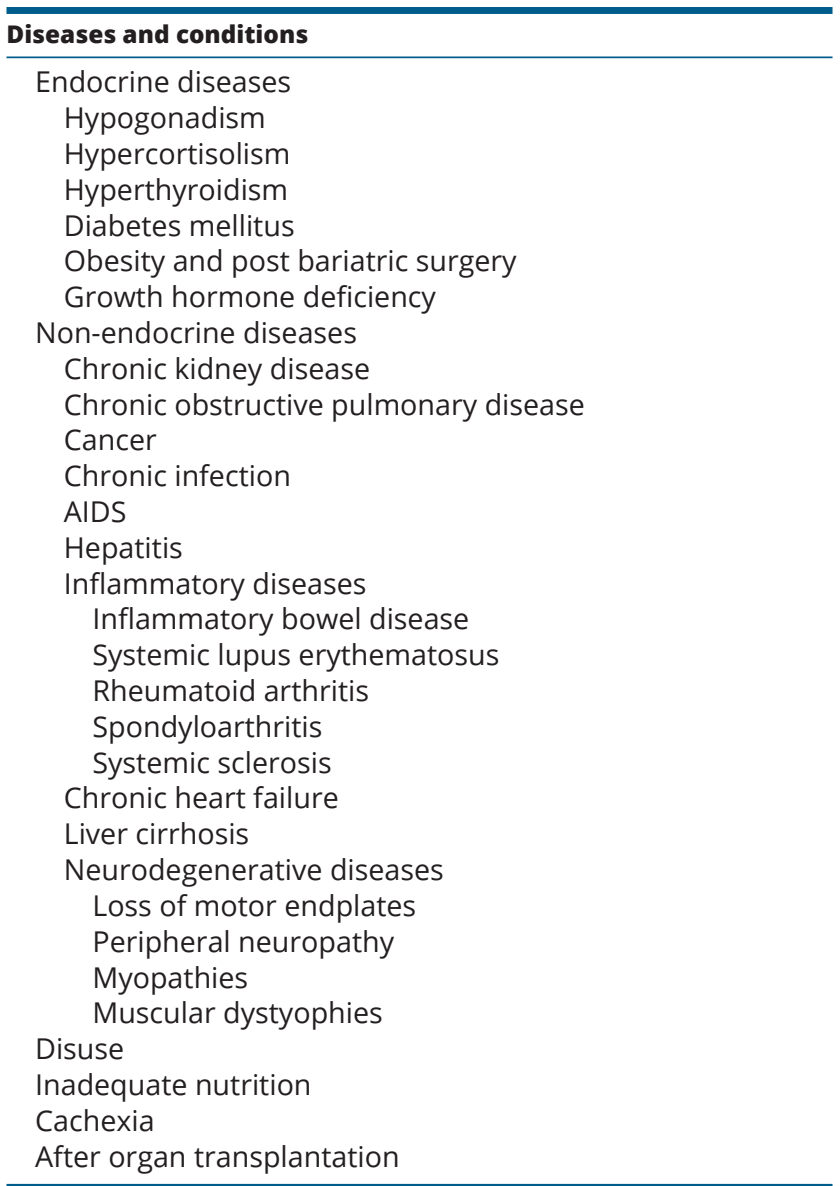

AIDS, acquired immune deficiency syndrome. 


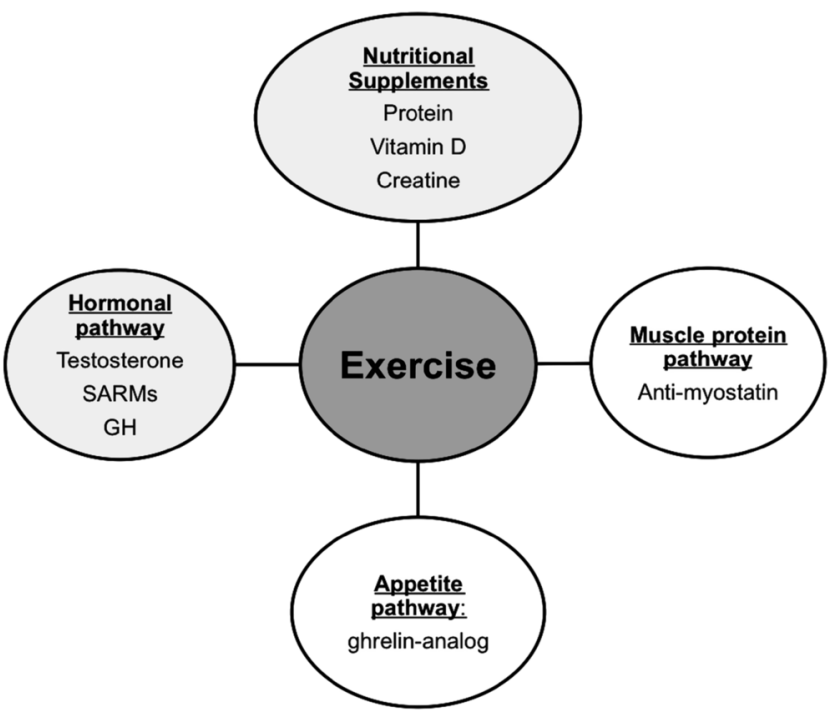

\section{Figure 3}

Proposal tools for prevention and treatment of sarcopenia. Exercise by itself is effective for the prevention and treatment and also has an interactive effect with the others. GH, growth hormone; SARM, selective androgen receptor modulator.

\section{Exercise}

The effects of resistance training (RT), in terms of increasing MM and strength, are well known in both young and older individuals (78). In a systematic review of 37 randomized clinical trials (RCT), an exercise intervention yielded an improved $\mathrm{MM}$ in $79 \%$ of the trials, muscle strength in $82 \%$ and physical performance in $92.8 \%$. However, all end points showed the small benefit of additional dietary supplementation (79).

The American College of Sports Medicine (ACSM) recommends that exercise intervention employ the FITT-VP principle, which refers to the frequency (F), intensity (I), time (T) and type (T) of exercise, along with its volume $(\mathrm{V})$ and progression $(\mathrm{P})$ over time in an individualized exercise training program that should be adapted to the primary disease causing a specific patient's physical condition. The literature strongly recommends moderate-to-high-intensity resistance exercise training to treat sarcopenia (80). In fact, RT increased mixed muscle protein synthesis, leading to a hypertrophy of type II muscle fiber; protein supplementation may increment the muscle hypertrophy induced by RT.

\section{Nutritional supplements}

Poor nutrition is related to weakness; therefore, good nutrition is a modifiable risk factor for sarcopenia, and specific nutrients are potential targets for improving physical function in older adults (81).

Vitamin D supplementation plays a role in the treatment of sarcopenia. Cross-sectional and observational studies have found an association between low levels of 25 hydroxyvitamin D (25OHD) and low MM and muscle loss. A great number of randomized studies evaluated how vitamin D supplementation affected muscle function and found a demonstrable improvement in balance and function. A meta-analysis found a 14-34\% decrease in falls, with the strongest effect on those individuals with lower baseline levels of 25OHD (82). By contrast, other trials have not shown similarly positive results, probably because of the inclusion of subjects without vitamin D deficiency or because the supplementation was with relatively low doses of vitamin D (83). Based on vitamin D's positive effect on muscle function, guidelines have recommended a daily average vitamin D intake of at least 1000 UI-4000 UI for all elderly adults, to reduce the risk of falls (84).

The relationship between protein intake and MM is well known; the average intake for elderly patients is below $0.8 \mathrm{~g} / \mathrm{kg} / \mathrm{day}$, and thus, below the recommended $1-1.2 \mathrm{~g} / \mathrm{kg} /$ day for healthy elderly people and $1.2-1.5 \mathrm{~g} / \mathrm{kg} /$ day for geriatric patients with acute and chronic diseases (85). The studies involving protein supplementation in the prevention and treatment of sarcopenia relied on heterogeneous protocols in terms of dosage, varying from 7.4 to $45 \mathrm{~g}$ of protein per day, as well as duration of study. Higher protein doses ( $40 \mathrm{~g}$ per day) demonstrated an interactive effect, between protein supplementation and exercise, on muscle function in elderly patients, as well as in frail individuals (86). The best time for protein consumption is still controversial: protein pulse feeding seems to provide better retention and postprandial amino acid concentrations; the within-day protein distribution improved protein synthesis and frequent consumption of protein at breakfast and lunch preserved lean mass. Evidently, the most important factor is to ensure that sarcopenic patients consume an adequate daily amount of proteins.

Under pathological conditions, dietary proteins fail to produce postprandial muscular protein synthesis (MPS), which refers to whether patients have the necessary essential amino acids (mainly leucine, but also glutamine and arginine), to induce an impact on MPS. If ingested following a RT session, protein increases amino acid delivery to the muscle through blood flow and mTOR pathway activation (79).

A combination of dietary supplements and ageappropriate exercise has also demonstrated significant 
beneficial effects on sarcopenia. A randomized doubleblinded, placebo-controlled study (RCT), over 12 weeks, evaluated 130 sarcopenic elderly subjects (80.3 years), supplemented with whey protein, amino acids and vitamin $\mathrm{D}$, along with exercise, showed an increase of fat-free mass and strength, whereas $68 \%$ of participants became non-sarcopenic (87). Similarly, a combination of a higher dose of vitamin D (800 UI) and leucine-enriched (3g) whey protein (20g) resulted in improved handgrip strength and SPPB scores among sarcopenic elderly patients (88)

\section{Other pharmacological agents}

Creatine is a popular dietary supplement used by athletic subjects. A beneficial effect of creatine, in a dose of $5 \mathrm{~g} /$ day, on MM and strength, has been reported in individuals over 65 years of age (89). In fact, creatine supplementation has been thought to augment lean mass by increasing training volume, as well as by activating satellite cells and specific muscle growth factors (e.g., IGF-1, 4EBP1) (85). Meta-analysis results support a role for creatine supplementation during RT as an enhancer of MM gain, strength and functional performance (90).

Testosterone replacement therapy produces an improvement in LM and strength among older healthy and hypogonadal men. Further, improvements in skeletal muscle function, after testosterone replacement therapy, are fiber-type dependent and restricted to increases in cell size, peak force and peak power (91). More recently, a nonsteroidal, selective androgen receptor modulator (SARM) has been under investigation for treatment of functional limitations. SARMs bind to the androgen receptor and act as potent androgenic agonists in selective target tissues, such as muscle and bone. An RCT, involving older adults with sarcopenia, evaluated the effect of SARM (MK-0773) and found no beneficial effects on muscle function. Other SARMs (e.g. LGD-4033, BMS-564929, enobosarm) have been tested on sarcopenic elderly individuals and had no advantage over testosterone $(92,93)$.

\section{Anti-myostatin therapy}

Myostatin, a member of the TGF $\beta$ superfamily, binds to activin receptor IIb8 and inhibits muscle protein synthesis through the AKT-mTOR pathway; it is highly expressed in skeletal muscle cells (94). The strategies for decreasing its effects include treatment with faulty myostatin receptors, anti-myostatin antibodies and antibodies to the myostatin receptor, ActRIIB. All these treatments produced some beneficial effect on MM, and on at least one functional criterion. In postmenopausal women, the faulty myostatin receptor ACE-031 showed significant increases in total LM and thigh muscle volume. A 36-week, phase II trial with the anti-myostatin antibody LY2495655, on over 200 older sarcopenic individuals, resulted in increased lean mass and improved performance on the stair climb and chair rise, as well as faster gait speed. The results, with anti-ActRIIB antibody bimagrumab (BYM338), are dubious, increasing $\mathrm{MM}$ in patients with COPD-induced cachexia, as well as MM and function in patients with sarcopenia, but showing no effects on patients with myositis.

Moreover, newer types of treatment have been developed, including anabolic agents, anti-cytokines, as well as drugs intended to promote appetite and body weight, such as anamorelin, an oral ghrelin-analog, indicated when anorexia-cachexia is responsible for the sarcopenia (87).

\section{Conclusions}

Sarcopenia is a frequent disorder that affects elderlies and non-aging patients with chronicillnesses, which can impact unfavorable in the disease outcome. The pathophysiology involves different mechanisms specific for each disease overlapping with aging process of sarcopenia. Diagnostic should be based on clinical suspicion, evaluation of muscle strength, muscle quantification and performance. The awareness of the presentation of sarcopenia in the clinical context of other diseases is fundamental to ensure that preventive measures can be deployed.

\section{Declaration of interest}

The author Cesar Luiz Boguszewski is the Associate Editor of European Journal of Endocrinology for South America. He was not involved in the editorial process for this paper. The other authors declare that there is no conflict of interest that could be perceived as prejudicing the impartiality of the research reported.

\section{Funding}

This research did not receive any specific grant from any funding agency in the public, commercial or not-for-profit sector.

\section{References}

1 Cruz-Jentoft AJ, Baeyens JP, Bauer JM, Boirie Y, Cederholm T, Landi F, Martin FC, Michel JP, Rolland Y, Schneider SM et al. Sarcopenia: European consensus on definition and diagnosis: report of the European Working Group on Sarcopenia in older people. Age and Ageing 201039 412-423. (https://doi.org/10.1093/ageing/afq034) 
2 Shafiee G, Keshtkar A, Soltani A, Ahadi Z, Larijani B \& Heshmat R. Prevalence of sarcopenia in the world: a systematic review and meta- analysis of general population studies. Journal of Diabetes and Metabolic Disorders 201716 21. (https://doi.org/10.1186/s40200-0170302-x)

3 Tournadre A, Vial G, Capel F, Soubrier M \& Boirie Y. Sarcopenia. Joint Bone Spine 201886 39-45. (https://doi.org/10.1016/j. jbspin.2018.08.001)

4 Kalyani RR, Corriere M \& Ferrucci L. Age-related and disease-related muscle loss: the effect of diabetes, obesity, and other diseases. Lancet Diabetes and Endocrinology 20142 819-829. (https://doi.org/10.1016/ S2213-8587(14)70034-8)

5 Locquet M, Beaudart C, Hajaoui M, Petermans J, Reginster JY \& Bruyère $\mathrm{O}$. Three-year adverse health consequences of sarcopenia in community-dwelling older adults according to 5 diagnosis definitions. Journal of the American Medical Directors Association 2019 20 43-46.e2. (https://doi.org/10.1016/j.jamda.2018.06.004) 6 Dionyssiotis Y, Kapsokoulou A, Samlidi E, Angoules AG, Papathanasiou J, Chronopoulos E, Kostoglou-Athanassiou I \& Trovas G. Sarcopenia: from definition to treatment. Hormones 2017 16 429-439. (https://doi.org/10.14310/horm.2002.1764)

7 Cruz-Jentoft AJ, Bahat G, Bauer J, Boirie Y, Bruyère O, Cederholm T, Cooper C, Landi F, Rolland Y, Sayer AA et al. Writing Group for the European. Working Group on Sarcopenia in Older People 2 (EWGSOP2), and the Extended Group for EWGSOP2 I, Baeyens JP, Cesari M, Cherubini A, Kanis J, Maggio M, Martin F, Michel JP, Pitkala K, Reginster JY, Rizzoli R, Sánchez-Rodríguez D, \& Schols J. Sarcopenia: revised European consensus on definition and diagnosis. Age and Ageing 201848 16-31. (https://doi.org/10.1093/ageing/ afy169)

8 Baumgartner RN, Koehler KM, Gallagher D, Romero L, Heymsfield SB, Ross RR, Garry PJ \& Lindeman RD. Epidemiology of sarcopenia among the elderly in New Mexico. American Journal of Epidemiology 1998147 755-763. (https://doi.org/10.1093/ oxfordjournals.aje.a009520)

9 Studenski SA, Peters KW, Alley DE, Cawthon PM, McLean RR, Harris TB, Ferrucci L, Guralnik JM, Fragala MS, Kenny AM et al. The FNIH sarcopenia project: rationale, study description, conference recommendations, and final estimates. Journals of Gerontology: Series A, Biological Sciences and Medical Sciences 201469 547-558. (https:// doi.org/10.1093/gerona/glu010)

10 Chen LK, Liu LK, Woo J, Assantachai P, Auyeung TW, Bahyah KS, Chou MY, Chen LY, Hsu PS, Krairit O et al. Sarcopenia in Asia: consensus report of the Asian working group for sarcopenia. Journal of the American Medical Directors Association 201415 95-101. (https:// doi.org/10.1016/j.jamda.2013.11.025)

11 Fielding RA, Vellas B, Evans WJ, Bhasin S, Morley JE, Newman AB, Abellan van Kan G, Andrieu S, Bauer J, Breuille D et al. Sarcopenia: an undiagnosed condition in older adults. Current consensus definition: prevalence, etiology, and consequences. International Working Group on Sarcopenia. Journal of the American Medical Directors Association 201112 249-256. (https://doi.org/10.1016/j. jamda.2011.01.003)

12 Morley JE, Abbatecola AM, Argiles JM, Baracos V, Bauer J, Bhasin S, Cederholm T, Coats AJS, Cummings SR, Evans WJ et al. Sarcopenia with limited mobility: an international consensus. Journal of the American Medical Directors Association 201112 403-409. (https://doi. org/10.1016/j.jamda.2011.04.014)

13 Dent E, Morley JE, Cruz-Jentoft AJ, Arai H, Kritchevsky SB, Guralnik J, Bauer JM, Pahor M, Clark BC, Cesari M et al. International clinical practice guidelines for sarcopenia (ICFSR): screening, diagnosis and management. Journal of Nutrition, Health and Aging 201822 1148-1161. (https://doi.org//10.1007/s12603-018-1139-9)

14 Alley DE, Shardell MD, Peters KW, McLean RR, Dam TTL, Kenny AM, Fragala MS, Harris TB, Kiel DP, Guralnik JM et al. Grip strength cutpoints for the identification of clinically relevant weakness.
Journals of Gerontology: Series A, Biological Sciences and Medical Sciences 201469 559-566. (https://doi.org/10.1093/gerona/glu011)

15 Cawthon PM, Peters KW, Shardell MD, McLean RR, Dam TTL, Kenny AM, Fragala MS, Harris TB, Kiel DP, Guralnik JM et al. Cutpoints for low appendicular lean mass that identify older adults with clinically significant weakness. Journals of Gerontology: Series A, Biological Sciences and Medical Sciences 201469 567-575. (https://doi. org/10.1093/gerona/glu023)

16 Dam TT, Peters KW, Fragala M, Cawthon PM, Harris TB, McLean R, Shardell M, Alley DE, Kenny A, Ferrucci L et al. An evidence-based comparison of operational criteria for the presence of sarcopenia. Journals of Gerontology - Series A: Biological Sciences and Medical Sciences 2014 69A 567-575. (https://doi.org/10.1093/gerona/glu013)

17 Rossi AP, Micciolo R, Rubele S, Fantin F, Caliari C, Zoico E, Mazzali G, Ferrari E, Volpato S \& Zamboni M. Assessing the risk of sarcopenia in the elderly : the mini sarcopenia risk assessment (Msra) questionnaire. Journal of Nutrition, Health and Aging 201721 743-749. (https://doi.org/10.1007/s12603-017-0921-4)

18 Malmstrom TK \& Morley JE. SARC-F: a simple questionnaire to rapidly diagnose sarcopenia. Journal of the American Medical Directors Association 201314 531-532. (https://doi.org/10.1016/j. jamda.2013.05.018)

19 Jones CJ, Rikli RE \& Beam WC. A 30-s chair-stand test as a measure of lower body strength in community-residing older adults. Research Quarterly for Exercise and Sport 199970 113-119. (https://doi.org/10.1 080/02701367.1999.10608028)

20 Podsiadlo D \& Richardson S. The timed 'Up \& Go': a test of basic functional mobility for frail elderly persons. Journal of the American Geriatrics Society 199139 142-148. (https://doi. org/10.1111/j.1532-5415.1991.tb01616.x)

21 Tosato M, Marzetti E, Cesari M, Savera G, Miller RR, Bernabei R, Landi F \& Calvani R. Measurement of muscle mass in sarcopenia: from imaging to biochemical markers. Aging Clinical and Experimental Research 201729 19-27. (https://doi.org/10.1007/s40520-016-0717-0)

22 Stringer HJ \& Wilson D. The role of ultrasound as a diagnostic tool for sarcopenia. Journal of Frailty and Aging $20187258-261$. (https:// doi.org/10.14283/jfa.2018.24)

23 Kawakami R, Murakami H, Sanada K, Tanaka N, Sawada SS, Tabata I, Higuchi M \& Miyachi M. Calf circumference as a surrogate marker of muscle mass for diagnosing sarcopenia in Japanese men and women. Geriatrics and Gerontology International 201515 969-976. (https://doi. org/10.1111/ggi.12377)

24 Makarevich AE \& Lemiasheuskaya S. Dynamics of body composition in male patients during chronic obstructive pulmonary disease (COPD) development. Pneumonologia i Alergologia Polska 201583 424-430. (https://doi.org/10.5603/PiAP.2015.0070)

25 Munhoz da Rocha Lemos Costa T, Costa FM, Jonasson TH, Moreira CA, Boguszewski CL \& Borba VZC. Body composition and sarcopenia in patients with chronic obstructive pulmonary disease. Endocrine 201860 95-102. (https://doi.org/10.1007/s12020-0181533-4)

26 Jones SE, Maddocks M, Kon SSC, Canavan JL, Nolan CM, Clark AL, Polkey MI \& Man WDC. Sarcopenia in COPD: prevalence, clinical correlates and response to pulmonary rehabilitation. Thorax $2015 \mathbf{7 0}$ 213-218. (https://doi.org/10.1136/thoraxjnl-2014-206440)

27 Pereira RA, Cordeiro AC, Avesani CM, Carrero JJ, Lindholm B, Amparo FC, Amodeo C, Cuppari L \& Kamimura MA. Sarcopenia in chronic kidney disease on conservative therapy: prevalence and association with mortality. Nephrology, Dialysis, Transplantation 2015 30 1718-1725. (https://doi.org/10.1093/ndt/gfv133)

28 Kim JK, Kim SG, Oh JE, Lee YK, Noh JW, Kim HJ \& Song YR. Impact of sarcopenia on long-term mortality and cardiovascular events in patients undergoing hemodialysis. Korean Journal of Internal Medicine 2017 Epub. (https://doi.org/10.3904/kjim.2017.083)

29 Saitoh M, Ishida J, Doehner W, von Haehling S, Anker MS, Coats AJS, Anker SD \& Springer J. Sarcopenia, cachexia, and muscle 
performance in heart failure: review update 2016. International Journal of Cardiology 2017238 5-11. (https://doi.org/10.1016/j. ijcard.2017.03.155)

30 Hajahmadi M, Shemshadi S, Khalilipur E, Amin A, Taghavi S, Maleki M, Malek H \& Naderi N. Muscle wasting in young patients with dilated cardiomyopathy. Journal of Cachexia, Sarcopenia and Muscle 20178 542-548. (https://doi.org/10.1002/jcsm.12193)

31 Ryan E, McNicholas D, Creavin B, Kelly ME, Walsh T \& Beddy D. Sarcopenia and inflammatory bowel disease: a systematic review. Inflammatory Bowel Diseases 201925 67-73. (https://doi.org/10.1093/ ibd/izy212)

32 Barone M, Viggiani MT, Anelli MG, Fanizzi R, Lorusso O, Lopalco G, Cantarini L, Di A, Lapadula G \& Iannone F. Sarcopenia in patients with rheumatic diseases: prevalence and associated risk factors. Journal of Clinical Medicine 20187 504. (https://doi.org/10.3390/ jcm7120504)

33 Peterson SJ \& Mozer M. Differentiating sarcopenia and cachexia among patients with cancer. Nutrition in Clinical Practice 201732 30-39. (https://doi.org/10.1177/0884533616680354)

34 Shachar SS, Williams GR, Muss HB \& Nishijima TF. Prognostic value of sarcopenia in adults with solid tumours: a meta-analysis and systematic review. European Journal of Cancer 201657 58-67. (https:// doi.org/10.1016/j.ejca.2015.12.030)

35 Trierweiler H, Kisielewicz G, Hoffmann Jonasson T, Rasmussen Petterle R, Aguiar Moreira C \& Zeghbi Cochenski Borba V. Sarcopenia: a chronic complication of type 2 diabetes mellitus. Diabetology and Metabolic Syndrome 201810 25. (https://doi. org/10.1186/s13098-018-0326-5)

36 Hamasaki H, Kawashima Y, Katsuyama H, Sako A, Goto A \& Yanai H. Association of handgrip strength with hospitalization, cardiovascular events, and mortality in Japanese patients with type 2 diabetes. Scientific Reports 20177 7041. (https://doi.org/10.1038/s41598-01707438-8)

37 McKee A, Morley JE, Matsumoto AM \& Vinik A. Sarcopenia: an endocrine disorder? Endocrine Practice 201723 1140-1149. (https:// doi.org/10.4158/EP171795.RA)

38 Yoon JW, Ha YC, Kim KM, Moon JH, Choi SH, Lim S, Park YJ, Lim JY, Kim KW, Park KS et al. Hyperglycemia is associated with impaired muscle quality in older men with diabetes: the Korean longitudinal study on health and aging. Diabetes and Metabolism Journal $2016 \mathbf{4 0}$ 140-146. (https://doi.org/10.4093/dmj.2016.40.2.140)

39 Bouchi R, Fukuda T, Takeuchi T, Nakano Y, Murakami M, Minami I, Izumiyama $\mathrm{H}$, Hashimoto $\mathrm{K}$, Yoshimoto T \& Ogawa Y. Association of sarcopenia with both latent autoimmune diabetes in adults and type 2 diabetes: a cross-sectional study. Journal of Diabetes and Its Complications 201731 992-996. (https://doi.org/10.1016/j. jdiacomp.2017.02.021)

40 Polyzos SA \& Margioris AN. Sarcopenic obesity. Hormones 201817 321-331. (https://doi.org/10.1007/s42000-018-0049-x)

41 Barazzoni R, Bischoff S, Boirie Y, Busetto L, Cederholm T, Dicker D, Toplak H, Gossum A Van, Yumuk V \& Vettor R. Sarcopenic obesity: time to meet the challenge. Obesity Facts 201811 294-305. (https:// doi.org/10.1159/000490361)

42 Batsis JA, Mackenzie TA, Emeny RT, Lopez-Jimenez F \& Bartels SJ. Low lean mass with and without obesity, and mortality: results From the 1999-2004 national health and nutrition examination survey. Journals of Gerontology: Series A, Biological Sciences and Medical Sciences 201772 1445-1451. (https://doi.org/10.1093/gerona/glx002)

43 Batsis JA, Barre LK, Mackenzie TA, Pratt SI, Lopez-Jimenez F \& Bartels SJ. Variation in the prevalence of sarcopenia and sarcopenic obesity in older adults associated with different research definitions: dual-energy X-ray absorptiometry data from the national health and nutrition examination survey 1999-2004. Journal of the American Geriatrics Society 201361 974-980. (https://doi.org/10.1111/jgs.12260)

44 Vaurs C, Diméglio C, Charras L, Anduze Y, Chalret du Rieu M \& Ritz P. Determinants of changes in muscle mass after bariatric surgery. Diabetes and Metabolism 201541 416-421. (https://doi. org/10.1016/j.diabet.2015.04.003)

45 Otto M, Elrefai M, Krammer J, Weiß C, Kienle P \& Hasenberg T. Sleeve gastrectomy and Roux-en-Y gastric bypass lead to comparable changes in body composition after adjustment for initial body mass index. Obesity Surgery 201626 479-485. (https://doi.org/10.1007/ s11695-015-1792-6)

46 Minetto MA, Lanfranco F, Motta G, Allasia S, Arvat E \& D'Antona G. Steroid myopathy: some unresolved issues. Journal of Endocrinological Investigation 201134 370-375. (https://doi.org/10.1007/BF03347462)

47 Minetto MA, Qaisar R, Agoni V, Motta G, Longa E, Miotti D, Pellegrino MA \& Bottinelli R. Quantitative and qualitative adaptations of muscle fibers to glucocorticoids. Muscle and Nerve 201552 631-639. (https://doi.org/10.1002/mus.24572)

48 Ferrando AA, Stuart CA, Sheffield-Moore M \& Wolfe RR. Inactivity amplifies the catabolic response of skeletal muscle to cortisol. Journal of Clinical Endocrinology and Metabolism 199984 3515-3521. (https:// doi.org/10.1210/jcem.84.10.6046)

49 Kim JH, Kwak MK, Ahn SH, Kim H, Cho YY, Suh S, Kim BJ, Song KH, Lee SH \& Koh JM. Alteration in skeletal muscle mass in women with subclinical hypercortisolism. Endocrine 201861 134-143. (https:// doi.org/10.1007/s12020-018-1598-0)

50 Berr CM, Stieg MR, Deutschbein T, Quinkler M, Schmidmaier R, Osswald A, Reisch N, Ritzel K, Dimopoulou C, Fazel J et al. Persistence of myopathy in Cushing's syndrome: evaluation of the German Cushing's Registry. European Journal of Endocrinology 2017 176 737-746. (https://doi.org/10.1530/EJE-16-0689)

51 Hirschfeld HP, Kinsella R \& Duque G. Osteosarcopenia: where bone, muscle, and fat collide. Osteoporosis International 201728 2781-2790. (https://doi.org/10.1007/s00198-017-4151-8)

52 Hassan EB \& Duque G. Osteosarcopenia: a new geriatric syndrome. Australian Family Physician 201746 849-853.

53 Paintin J, Cooper C \& Dennison E. Osteosarcopenia. British Journal of Hospital Medicine 201879 253-258. (https://doi.org/10.12968/ hmed.2018.79.5.253)

54 Huo YR, Suriyaarachchi P, Gomez F, Curcio CL, Boersma D, Muir SW, Montero-Odasso M, Gunawardene P, Demontiero O \& Duque G. Phenotype of osteosarcopenia in older individuals with a history of falling. Journal of the American Medical Directors Association 201516 290-295. (https://doi.org/10.1016/j.jamda.2014.10.018)

55 Wang YJ, Wang Y, Zhan JK, Tang ZY, He JY, Tan P, Deng HQ, Huang W \& Liu YS. Sarco-osteoporosis: prevalence and association with frailty in Chinese community-dwelling older adults. International Journal of Endocrinology 20152015 482940. (https://doi. org/10.1155/2015/482940)

56 Yoo JIl, Kim H, Ha YC, Kwon HB \& Koo KH. Osteosarcopenia in patients with hip fracture is related with high mortality. Journal of Korean Medical Science 201833 e27. (https://doi.org/10.3346/ jkms.2018.33.e27)

57 Giustina A, Mazziotti G \& Canalis E. Growth hormone, insulin-like growth factors, and the skeleton. Endocrine Reviews 200829 535-559. (https://doi.org/10.1210/er.2007-0036)

58 Corpas E, Harman SM \& Blackman MR. Human growth hormone and human aging. Endocrine Reviews 199314 20-39. (https://doi. org/10.1210/edrv-14-1-20)

59 Bartke A. Growth hormone and aging: updated review. World Journal of Men's Health 201937 19-30. (https://doi.org/10.5534/ wjmh.180018)

60 Pollock RD, Carter S, Velloso CP, Duggal NA, Lord JM, Lazarus NR \& Harridge SDR. An investigation into the relationship between age and physiological function in highly active older adults. Journal of Physiology 2015593 657-680. (https://doi.org/10.1113/ jphysiol.2014.282863)

61 Nass R, Pezzoli SS, Oliveri MC, Patrie JT, Harrell FE, Clasey JL, Heymsfield SB, Bach MA, Vance ML \& Thorner MO. Effects of an oral ghrelin mimetic on body composition and clinical outcomes in 
healthy older adults: a randomized trial. Annals of Internal Medicine 2008149 601-611. (https://doi.org/10.7326/0003-4819-149-9200811040-00003)

62 White HK, Petrie CD, Landschulz W, MacLean D, Taylor A, Lyles K, Wei JY, Hoffman AR, Salvatori R, Ettinger MP et al. \& Capromorelin Study Group. Effects of an oral growth hormone secretagogue in older adults. Journal of Clinical Endocrinology and Metabolism 200994 1198-1206. (https://doi.org/10.1210/jc.2008-0632)

63 Chen LY, Wu YH, Liu LK, Lee WJ, Hwang AC, Peng LN, Lin MH \& Chen LK. Association among serum insulin-like growth factor-1, frailty, muscle mass, bone mineral density, and physical performance among community-dwelling middle-aged and older adults in Taiwan. Rejuvenation Research 201821 270-277. (https://doi.org/10.1089/ rej.2016.1882)

64 Nieuwpoort IC van, Vlot MC, Schaap LA, Lips P \& Drent ML. The relationship between serum IGF-1, handgrip strength, physical performance and falls in elderly men and women. European Journal of Endocrinology 2018179 73-84. (https://doi.org/10.1530/EJE-18-0076)

65 Velloso CP. Regulation of muscle mass by growth hormone and IGF-I. British Journal of Pharmacology 2008154 557-568. (https://doi. org/10.1038/bjp.2008.153)

66 Brat O, Ziv I, Klinger B, Avraham M \& Laron Z. Muscle force and endurance in untreated and human growth hormone or insulin-like growth factor-I-treated patients with growth hormone deficiency or Laron syndrome. Hormone Research 199747 45-48. (https://doi. org/10.1159/000185429)

67 Boguszewski CL. Update on GH therapy in adults. F1000Research 20176 2017. (https://doi.org/10.12688/f1000research.12057.1)

68 Andrade-Guimarães AL, Aguiar-Oliveira $\mathrm{MH}$, Salvatori R, Carvalho VO, Alvim-Pereira F, Daniel CRA, Brasileiro GAM, SantanaRibeiro AA, Santos-Carvalho HA, Oliveira CRP et al. Adult individuals with congenital, untreated, severe isolated growth hormone deficiency have satisfactory muscular function. Endocrine 201963 112-119. (https://doi.org/10.1007/s12020-018-1763-5)

69 Spiegeleer A De, Beckwée D, Bautmans I, Petrovic M \& Sarcopenia Guidelines Development group of the Belgian Society of Gerontology and Geriatrics (BSGG). Pharmacological interventions to improve muscle mass, muscle strength and physical performance in older people: an umbrella review of systematic reviews and meta-analyses. Drugs and Aging 201835 719-734. (https://doi.org/10.1007/s40266018-0566-y)

70 Sattler FR. Growth hormone in the aging male. Best Practice and Research: Clinical Endocrinology and Metabolism 201327 541-555. (https://doi.org/10.1016/j.beem.2013.05.003)

71 Götherström G, Elbornsson M, Stibrant-Sunnerhagen K, Bengtsson BA, Johannsson G \& Svensson J. Muscle strength in elderly adults with GH deficiency after 10 years of GH replacement. European Journal of Endocrinology 2010163 207-215. (https://doi. org/10.1530/EJE-10-0009)

72 Widdowson WM \& Gibney J. The effect of growth hormone replacement on exercise capacity in patients with GH deficiency: a metaanalysis. Journal of Clinical Endocrinology and Metabolism 200893 4413-4417. (https://doi.org/10.1210/jc.2008-1239)

73 Rubeck KZ, Bertelsen S, Vestergaard P \& Jørgensen JOL. Impact of GH substitution on exercise capacity and muscle strength in GH-deficient adults: a meta-analysis of blinded, placebo-controlled trials. Clinical Endocrinology 200971 860-866. (https://doi. org/10.1111/j.1365-2265.2009.03592.x)

74 Gates MA, Mekary RA, Chiu GR, Ding EL, Wittert GA \& Araujo AB. Sex steroid hormone levels and body composition in men. Journal of Clinical Endocrinology and Metabolism 201398 2442-2450. (https:// doi.org/10.1210/jc.2012-2582)

75 Kaufman JM \& Vermeulen A. The decline of androgen levels in elderly men and its clinical and therapeutic implications. Endocrine Reviews 200526 833-876. (https://doi.org/10.1210/er.2004-0013)
76 Zybek-Kocik A, Sawicka-Gutaj N, Szczepanek-Parulska E, Andrusiewicz M, Waligórska-Stachura J, Białas P, Krauze T, Guzik P, Skrobisz J \& Ruchała M. The association between irisin and muscle metabolism in different thyroid disorders. Clinical Endocrinology 2018 88 460-467. (https://doi.org/10.1111/cen.13527)

77 Boj-Carceller D, Sanz-París A, Sánchez-Oriz E, García-Foncillas López R, Calmarza-Calmarza P, Blay-Cortes V \& Abós-Olivares MD. Treatment of subclinical hyperthyroidism: effect on body composition. Nutricion Hospitalaria 201532 2331-2337. (https://doi. org $/ 10.3305 / \mathrm{nh} .2015 .32 .5 .9660$ )

78 Landi F, Marzetti E, Martone AM, Bernabei R \& Onder G. Exercise as a remedy for sarcopenia. Current Opinion in Clinical Nutrition and Metabolic Care 201417 25-31. (https://doi.org/10.1097/ MCO.0000000000000018)

79 Beaudart C, Dawson A, Shaw SC, Harvey NC, Kanis JA, Binkley N, Reginster JY, Chapurlat R, Chan DC, Bruyère $\mathrm{O}$ et al. Nutrition and physical activity in the prevention and treatment of sarcopenia: systematic review. Osteoporosis International 201728 1817-1833. (https://doi.org/10.1007/s00198-017-3980-9)

80 Zaleski AL, Taylor BA, Panza GA, Wu Y, Pescatello LS, Thompson PD $\&$ Fernandez $\mathrm{AB}$. Coming of age: considerations in the prescription of exercise for older adults. Methodist DeBakey Cardiovascular Journal 201612 98-104. (https://doi.org/10.14797/mdcj-12-2-98)

81 Kerstetter JE, Kenny AM \& Insogna KL. Dietary protein and skeletal health: a review of recent human research. Current Opinion in Lipidology 201122 16-20. (https://doi.org/10.1097/ MOL.0b013e3283419441)

82 Murad MH, Elamin KB, Abu Elnour NO, Elamin MB, Alkatib AA, Fatourechi MM, Almandoz JP, Mullan RJ, Lane MA, Liu H et al. Clinical review: the effect of vitamin D on falls: a systematic review and meta-analysis. Journal of Clinical Endocrinology and Metabolism 201196 2997-3006. . (https://doi.org/10.1210/jc.2011-1193)

83 Hansen KE, Johnson RE, Chambers KR, Johnson MG, Lemon CC, Vo TNT \& Marvdashti S. Treatment of vitamin D insufficiency in postmenopausal women: a randomized clinical trial. JAMA Internal Medicine 2015175 1612-1621. (https://doi.org/10.1001/ jamainternmed.2015.3874)

84 American Geriatrics Society. Workgroup on Vitamin D Supplementation for Older Adults, Judge J, Birge S, Gloth F 3rd, Heaney RP, Hollis BW, Kenny A, Kiel DP, Saliba D, Schneider DL \& Vieth R. Recommendations abstracted from the american geriatrics society consensus statement on vitamin $\mathrm{D}$ for prevention of falls and their consequences. Journal of the American Geriatrics Society 201462 147-152. (https://doi.org/10.1111/jgs.12631)

85 Deutz NEPP, Bauer JM, Barazzoni R, Biolo G, Boirie Y, BosyWestphal A, Cederholm T, Cruz-Jentoft A, Krznariç Z, Nair KS et al. Protein intake and exercise for optimal muscle function with aging: recommendations from the ESPEN Expert Group. Clinical Nutrition 201433 929-936 . (https://doi.org/10.1016/j. clnu.2014.04.007)

86 Chalé A, Cloutier GJ, Hau C, Phillips EM, Dallal GE \& Fielding RA. Efficacy of whey protein supplementation on resistance exerciseinduced changes in lean mass, muscle strength, and physical function in mobility-limited older adults. Journals of Gerontology: Series A, Biological Sciences and Medical Sciences 201368 682-690. (https://doi.org/10.1093/gerona/gls221)

87 Beaudart C, Dawson A, Shaw SC, Harvey NC, Kanis JA, Binkley N, Reginster JY, Chapurlat R, Chan DC, Bruyère $\mathrm{O}$ et al. Nutrition and physical activity in the prevention and treatment of sarcopenia: systematic review. Osteoporosis International 201728 1817-1833. (https://doi.org/10.1007/s00198-017-3980-9)

88 Rondanelli M, Klersy C, Terracol G, Talluri J, Maugeri R, Guido D, Faliva MA, Solerte BS, Fioravanti M, Lukaski H et al. Whey protein, amino acids, and vitamin D supplementation with physical activity increases fat-free mass and strength, functionality, and quality of life 
and decreases inflammation in sarcopenic elderly. American Journal of Clinical Nutrition 2016103 830-840. (https://doi.org/10.3945/ ajcn.115.113357)

89 Bauer JM, Verlaan S, Bautmans I, Brandt K, Donini LM, Maggio M, McMurdo MET, Mets T, Seal C, Wijers SL et al. Effects of a vitamin $\mathrm{D}$ and leucine-enriched whey protein nutritional supplement on measures of sarcopenia in older adults, the PROVIDE Study: a randomized, double-blind, placebo-controlled trial. Journal of the American Medical Directors Association 201516 740-747. (https://doi. org/10.1016/j.jamda.2015.05.021)

90 Kreider RB, Kalman DS, Antonio J, Ziegenfuss TN, Wildman R, Collins R, Candow DG, Kleiner SM, Almada AL \& Lopez HL. International Society of Sports Nutrition position stand: safety and efficacy of creatine supplementation in exercise, sport, and medicine. Journal of the International Society of Sports Nutrition 20171418. (https://doi.org/10.1186/s12970-017-0173-z)

91 Devries MC \& Phillips SM. Creatine supplementation during resistance training in older adults-a meta-analysis. Medicine and
Science in Sports and Exercise 201446 1194-1203. (https://doi. org/10.1249/MSS.0000000000000220)

92 Ferrando AA, Sheffield-Moore M, Paddon-Jones D, Wolfe RR \& Urban RJ. Differential anabolic effects of testosterone and amino acid feeding in older men. Journal of Clinical Endocrinology and Metabolism 200388 358-362. (https://doi.org/10.1210/jc.2002-021041)

93 Fitts RH, Peters JR, Dillon EL, Durham WJ, Sheffield-Moore M \& Urban RJ. Weekly versus monthly testosterone administration on fast and slow skeletal muscle fibers in older adult males. Journal of Clinical Endocrinology and Metabolism 2015100 E223-E231. (https://doi. org/10.1210/jc.2014-2759)

94 Dalton JT, Barnette KG, Bohl CE, Hancock ML, Rodriguez D, Dodson ST, Morton RA \& Steiner MS. The selective androgen receptor modulator GTx-024 (enobosarm) improves lean body mass and physical function in healthy elderly men and postmenopausal women: results of a double-blind, placebo-controlled phase II trial. Journal of Cachexia, Sarcopenia and Muscle 20112 153-161. (https:// doi.org/10.1007/s13539-011-0034-6)

Received 21 November 2018

Revised version received 13 March 2019

Accepted 26 March 2019 